
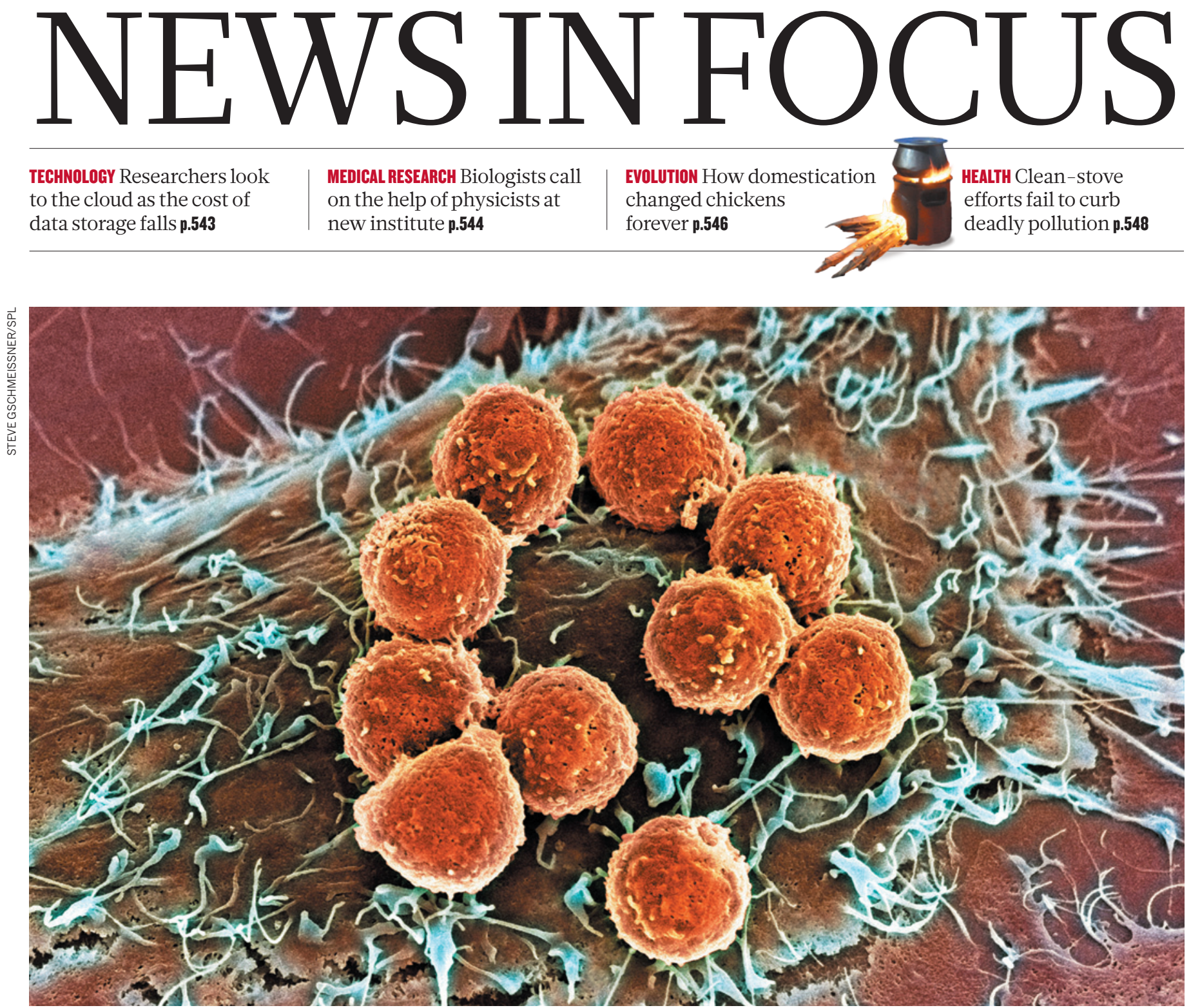

T cells (orange), which attach to and attack tumours, are fired up by immunotherapy treatments such as high-dose interleukin-2.

\title{
Old cancer drug gets fresh look
}

\section{Refinements to disfavoured immune therapy offer safer, more effective treatment.}

BY HEIDI LEDFORD

$\mathrm{W}$ hen Dave deBronkart was diagnosed with advanced kidney cancer in 2007, he learned about a treatment called high-dose interleukin-2 (IL-2) that fires up the body's immune system to fight the disease. The response rate was not great - tumours shrank in only about $15 \%$ of patients. And as many as $4 \%$ of people died from the treatment. But some of those who responded survived for years or even decades.

DeBronkart's prognosis was grim - only $8 \%$ of people with his disease survive for five years past diagnosis. He says that he was willing to risk what life he might have had left for the possibility of stopping his cancer's growth: "I said, 'Lethal side effects? OK."

Now, nearly seven years after his treatment, deBronkart's immune system continues to hold his cancer in check.

When researchers gather this week for the annual American Society of Clinical Oncology (ASCO) meeting in Chicago, Illinois, the spotlight will be on immunotherapies - a class of drugs that, like IL-2, kindle the immune system's ability to fend off cancer (see Nature 508, 24-26; 2014). Attendees will hear the latest about a new generation of these drugs - particularly those targeting a protein called PD-1, which cancers use to fend off immune-system attack. Pharmaceutical companies are racing to bring these PD-1 inhibitors to market.

Other data to be presented at the meeting suggest that IL-2, the drug that saved deBronkart and the first cancer immunotherapy approved by the US Food and Drug Administration (FDA), may be on the verge of a revival after having fallen out of favour. Two years after he finished the therapy, deBronkart learned that because of IL-2's risks, three-quarters of eligible patients are never told that it is an option. "There are patients who are dying without ever getting a potentially curative treatment," says Steven Rosenberg, an oncologist at the 
- US National Cancer Institute in Bethesda, Maryland. "It's a real problem."

IL-2 is a protein made by the body to spur the development of $\mathrm{T}$ cells in response to threats such as pathogens or cancer. Most cancer immunotherapies are designed to fire up T cells, but the effects can sometimes be deadly. Patients must be closely monitored while receiving highdose IL-2 treatment, because it can cause skin rashes, short-term neurological disturbances and dangerous drops in blood pressure.

Given the risks and the difficulty of administering high-dose IL-2, patients and doctors often baulk at using the treatment, which is approved in the United States for use against advanced melanoma and kidney cancer. But Howard Kaufman, a tumour immunologist at Rutgers Cancer Institute of New Jersey in New Brunswick, argues that IL-2's bad reputation is outdated. Fatalities have declined as physicians have learned how to manage side effects, he says. And data from Kaufman and others suggest that more patients benefit from the drug than previously realized.

At the ASCO meeting this week, Kaufman will present an analysis of IL-2 treatment in people who received the therapy for kidney cancer between 2007 and 2012. Tumours shrank in

only about $15 \%$ of patients, but they stopped growing in another $15 \%$. Those people, said to have 'stable' cancer, lived longer than people whose cancers kept growing after treatment.

Even so, the ther-

apy remains dangerous, warns Patrick Ott, a medical oncologist at Dana-Farber Cancer Institute in Boston, Massachusetts. "It can't be given at just any commu-

\section{"There are patients who are dying without ever getting apotentially curative treatment."} nity hospital," he says. "You need a real expert team to administer this treatment."

Ott and Kaufman are among researchers trying to make IL-2 therapy less toxic. At the meeting, they will describe their plans to test NHS-IL2, a fusion of IL-2 and an antibody that targets the DNA that is released by dying tumour cells. The antibody, developed by EMD Serono of Rockland, Massachusetts, directs IL-2 to tumour cells, helping to minimize its effects on healthy tissue. Another strategy, developed by a team led by John Frelinger, a cancer researcher at the University of Rochester Medical Center in New York, involves modifying IL-2 so that it is inactive until it encounters enzymes that are particularly abundant around tumour cells. "IL-2 was not meant to be expressed at high levels throughout the body," says Frelinger. "That's where the trouble with IL-2 therapy starts."

Others are experimenting with ways to expand the number of patients who respond to IL-2 treatment. In addition to activating cancer-fighting T cells, IL-2 stimulates regulatory $\mathrm{T}$ cells, which keep immune responses in check. Alkermes, a biotechnology company based in Dublin, is modifying the IL-2 protein so that it is less likely to activate regulatory $\mathrm{T}$ cells, and thus has the potential to generate a stronger immune response at lower doses. Because some of the toxic side effects of highdose IL-2 seem to be independent of immune responses, it is possible that the approach will provide a more tolerable therapy.

Newer therapies, including PD-1 inhibitors, have milder side effects than IL-2. But even if those therapies are approved by the FDA, Ott thinks that IL-2 treatments of some stripe will still have a role, especially for people who do not respond to other treatments. "High-dose IL-2 has a track record of patients who have been disease free for 20 years," says Ott. "And we just don't know that yet with the new drugs." -
OCEANOGRAPHY

\section{US Arctic research ship ready to cast off}

\section{Long-awaited vessel Sikuliaq joins an ageing fleet.}

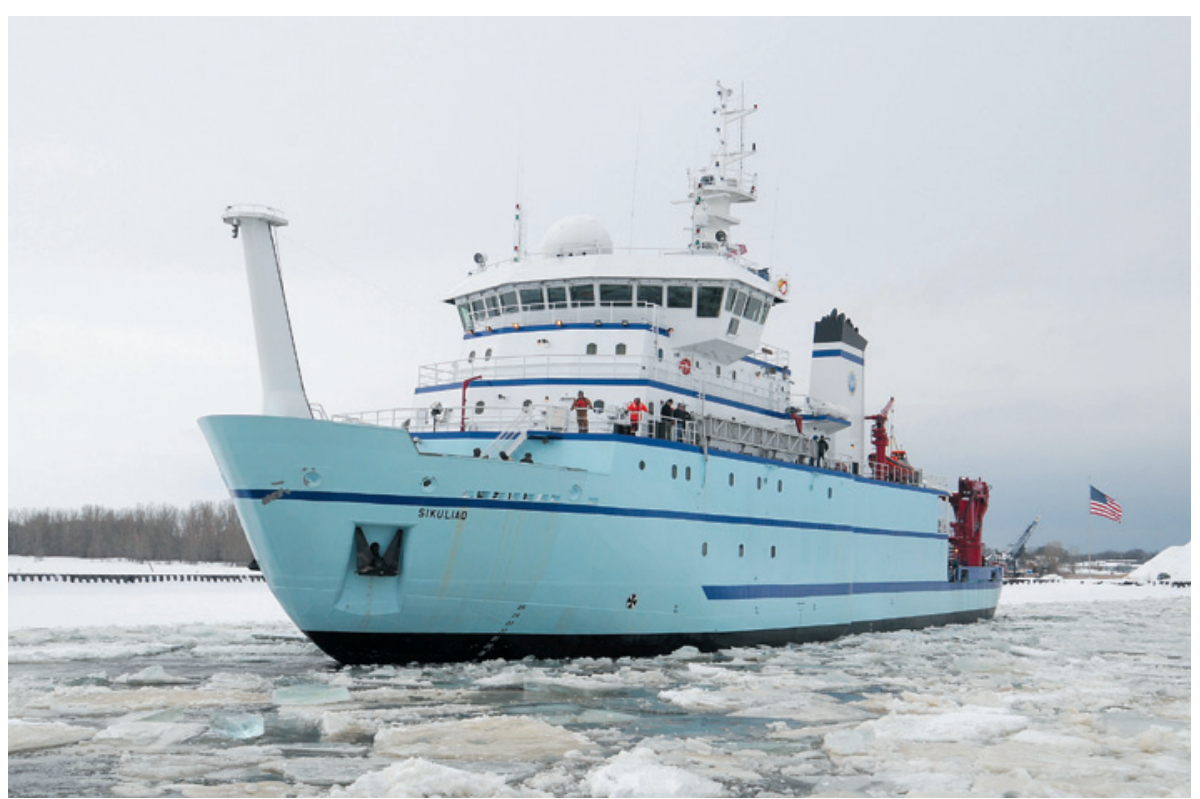

The latest addition to the US oceanographic research fleet will soon set off for its home port in Alaska.

\section{BY ALEXANDRA WITZE}

A brand-new research vessel is buoying the hopes of US oceanographers. In the first week of June, the University of Alaska Fairbanks plans to take possession of the RV Sikuliaq, a US\$200-million, 80-metre ship that is currently floating in the Great Lakes. It is the first research vessel built for the National Science Foundation (NSF) since 1981; polar scientists have been calling for a versatile icestrengthened ship for four decades.

"People ask, 'Why should the Arctic have a special ship'? It's a special place," says Vera Alexander, a biological oceanographer at the University of Alaska who has been involved in the campaign to build an Arctic research vessel. Plans call for the Sikuliaq to spend much of its time examining the effects of shrinking sea ice and other climate-change impacts on northern ecosystems.

The Sikuliaq's launch is particularly striking because most of the US oceanographicresearch fleet faces a grim future. Many of the other 23 vessels are ageing, and there is little money available to replace them. Construction of the Sikuliaq was made possible only because, in 2009, then-NSF director Arden Bement chose to give the project $\$ 148$ million from a government economic-stimulus package.

With its ability to navigate coastlines, icebound waters and the open sea, the Sikuliaq can explore a wide range of science questions, says Alexander. Biologists will be better able to track animal populations in places such 